\title{
Perception of SC/ST students participating in higher education with special reference to Mysore, Karnataka
}

\author{
Mahadevaswamy.M ${ }^{1 *}$, Dr. Sajan C.P $P^{2}$, Dr. G.Kotreshwar ${ }^{3}$ \\ ${ }^{I}$ Research scholar DOS in Commerce, Manasa Gangotri, University of Mysore, Mysore \\ \& Guest faculty, University Evening College, University of Mysore, Mysore \\ ${ }^{2}$ Research scholar $(P D F)$, search State key laboratory of advanced material synthesis and processing, Wuhan \\ University of Technology, Wuhan, Hubie, P.R China \\ ${ }^{3}$ professor, DOS in Commerce, Manasa Gangotri, University of Mysore, Mysore
}

\begin{abstract}
In the present dynamic world, higher education is so very important for handling the crucial/competitive business activities. It helps in sound decision making in terms of business concern and management program which directly impact the economic development of a nation.

The study aims to know the perception of SC/ST students participating towards higher education. SC/ST students are not able to enroll to higher education in Mysore district up to the mark as compared to other section of the society which is due to the social factors which are affecting them within our society. In order to know the root cause for fewer enrollments of students for higher education in Mysore city, survey was conducted in Mysore city colleges (Maharaj's college, Yuvaraja's collge, university evening college) and the collection of data was carried out through simple random sampling unit and structured questionnaire from prospective respondents. The analysis of data was done using statistical tools.
\end{abstract}

Keywords: perception, higher education, prospective, respondent.

\section{Introduction}

India has significant advantages in the present century knowledge chase. It has a large higher education sector - the third largest in the world in student numbers, after China and the United States. In India, English is primary language of higher education and research and has a long academic tradition where academic freedom is respected. There are a small number of high quality institutions, departments, and centers that can form the basis of quality sector in higher education. The fact is that, rather than the Central Government, the States exercise major responsibility for higher education which creates a cumbersome structure within a system which leads to a wide variety of policies and approaches.

However the weaknesses far balance the strengths. India educates approximately 10 per cent of its young people in higher education compared with more than half in the major industrialized countries and 15 per cent in China. Almost all of the world's academic systems look like a pyramid, with a small high quality platform at the top and a huge sector at the bottom. India occupies a small place in it, it's just because none of its Universities occupies a solid position at the top. A few of the best Universities have some excellent departments and centers, and there are a small number of exceptional undergraduate colleges. The University Grants Commission's recently supported major five Universities to build on their recognization strength is a step toward recognizing a differentiated academic system - and development excellence. At present, the world-class institutions are limited to the Indian Institutes of Technology (IITs), the Indian Institutes of Management (IIMs) and perhaps a few others such as the All India Institute of Medical Sciences and the Tata Institute of Fundamental Research. The combined enrollment of the students from these institution accounts of about only 1 per cent of the student population.

India cannot build internationally recognized research-oriented Universities quickly, but the country has the key elements in place to begin and sustain the process. India will need to create more Universities that can compete internationally to fully participate in the new world economy. Without these universities, India is destined to remain as a scientific backwater.

The participation of SC/ST students in higher education is very low as compare to other section of categories. These factors have been observed by the government and have provided so many incentives for participates in the higher education like scholarship, free hostel facilities. Special grant for library (it is exclusively utilized for SC/ST students) and no tuition fess.

\section{Objective of the study}

The main aim of the study is to know the perception of SC/ST students participating towards higher education in Mysore, Karnataka. In Mysore University SC/ST students' enrollment for higher education is very 
low. The present study is helpful to know the major factors that are affecting SC/ST student which are not letting them to participate in higher education.

\section{Research Methodology}

The primary data regarding the perception information of SC/ST students participating towards higher education in Mysore was collected through questionnaire and interaction with the students. Secondary data were collected various source like, internet, journals, and publications. Primary data and secondary data are analyzed thoroughly to achieve the objective of the study.

\section{Data analysis}

The data collected through random questionnaire from Mysore district among 54 respondents were segregated first in terms of their positive and negative perception towards participating in higher education. To know the difference in opinion among groups in terms of their household financial position, availability of existing facilities and secured marks in degree examination etc.,

\section{Data analysis and interpretation:}

The Primary data collected from the respondent were analyzed with the help of statistical tool, and the result are tabulated which is given in Table 1.

\begin{tabular}{|l|l|c|c|c|}
\hline \multirow{3}{*}{ District } & Factors & $\begin{array}{c}\text { Positive } \\
\text { response }\end{array}$ & $\begin{array}{c}\text { Negative } \\
\text { response }\end{array}$ & $\begin{array}{c}\text { Positive } \\
\text { Percentage (\%) }\end{array}$ \\
\hline \multirow{5}{*}{ Mysore } & Finance & 46 & 8 & 85 \\
\cline { 2 - 5 } & $\begin{array}{l}\text { Physical Facilities (lap-tap or computer facility } \\
\text { vehicle facility, accommodation facility) }\end{array}$ & 40 & 14 & 74 \\
\cline { 2 - 5 } & Lack of awareness & 35 & 19 & 64 \\
\cline { 2 - 5 } & Competition & 43 & 11 & 80 \\
\cline { 2 - 5 } & Responsibility & 49 & 5 & 91 \\
\hline
\end{tabular}

\section{Students' perception with respect to finance}

\begin{tabular}{|l|l|l|c|c|}
\hline District & Factors & Positive response & Negative response & $\begin{array}{c}\text { Positive Percentage } \\
(\%)\end{array}$ \\
\hline Mysore & Finance & 46 & 8 & 85 \\
\hline
\end{tabular}

The survey was conducted in Mysore district. The questionnaire was carried out with respect to perception towards higher education among 54 prospective respondents. In these 54 respondents 43 are male and 11 are female. According to the Respondent view higher education is not able for them to acquire because financial problems. Among overall respondents 46 of them strongly believe that finance is one of the major factors affecting higher education and the other 8 members expressed their views as finance factor is not the major which affects the students to participate in higher education. The graphical representation of response of students is given in Fig 1.

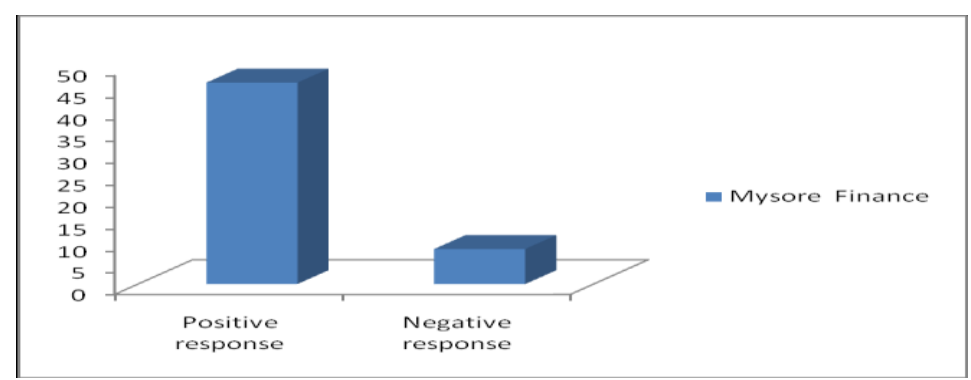

Figure1, Perception towards higher education with respect to finance.

\section{Students' perception with respect to physical facilities}

\begin{tabular}{|l|l|c|c|c|}
\hline District & Factors & Positive response & Negative response & Positive Percentage (\%) \\
\hline Mysore & Physical Facilities & 40 & 14 & 74 \\
\hline
\end{tabular}

Physical facilities also play a prominent role in perception of respondents towards higher education. According to the survey conducted most of the respondents are interested to take higher education. In the present case, total respondent is 54 . Among educated respondents $74 \%$ of them showed positive response and among uneducated $26 \%$ showed positive response towards higher education. According to the respondents physical requirement is very much essential for higher education which includes lap-tap (computer), vehicle facility, and accommodation facility. These are the factors which is very much essential. The results of the respondent 
Perception of SC/ST students participating in higher education with special reference to Mysore,

towards physical facilities obtained are given in Table 3 and the pictorial representation of the perception of respondents with respect to higher education is given in Fig 2.

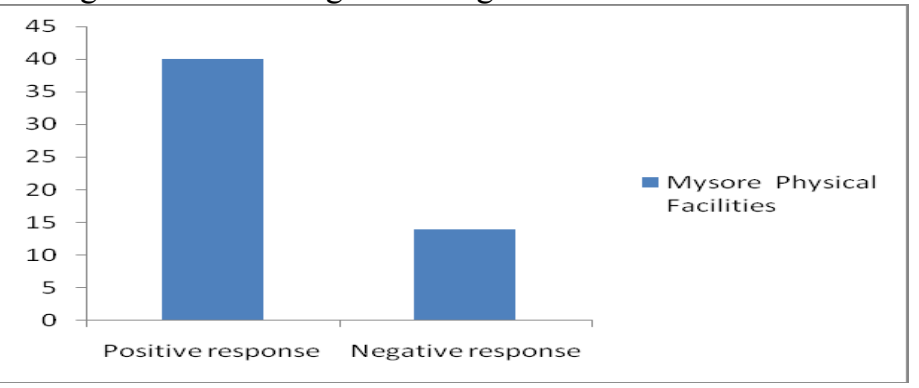

Figure2, Perception towards higher education with respect to physical facilities.

\section{Students' perception with respect to lack of awareness}

\begin{tabular}{|c|c|c|c|c|}
\hline District & Factors & Positive response & Negative response & Positive Percentage (\%) \\
\hline Mysore & Lack of awareness & 35 & 19 & 64 \\
\hline
\end{tabular}

Lack of awareness among people with respect to higher education can also be considered as a one of the reason less enrollment of students in Mysore district. As per the study carried out in Mysore most of the respondents have stated that they are not much aware about the benefits of higher education which clearly indicates that respondents do not have sufficient knowledge with respect to job opportunity and the social benefits they gain after having their higher education. The results obtained are given in Table 4 and the graphical representation of Students' perception with respect to lack of awareness is given in Fig 3. Based on the results obtained we can say that awareness about higher education is very much essential for the degree student.

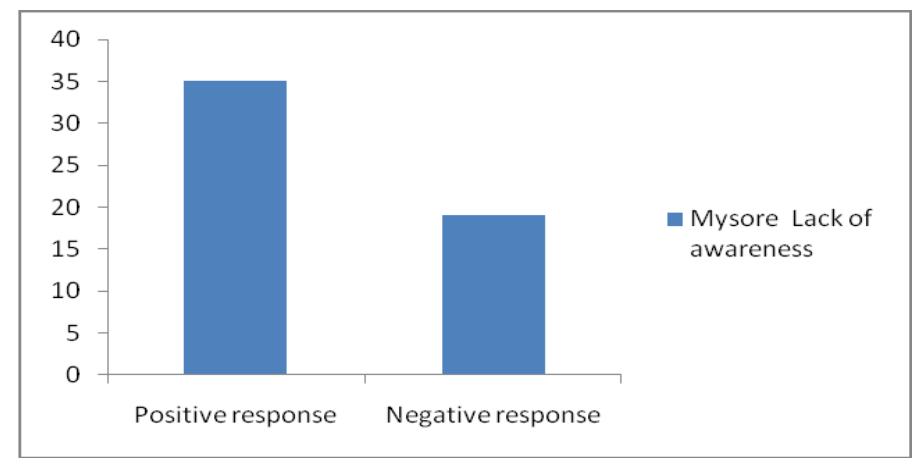

Figure3, Perception towards higher education with respect to lack of awareness.

\section{Students' perception with respect to Competition}

\begin{tabular}{|l|l|c|c|c|}
\hline District & Factors & Positive response & Negative response & Positive Percentage (\%) \\
\hline Mysore & Competition & 43 & 11 & 80 \\
\hline
\end{tabular}

Student perceptions towards higher education with respect to competition are given in Fig 4 and Table 5. During the questionnaire respondents said that today there is a lot of competition to higher education and to get enrolled to higher education a student should secure high marks in their degree examination. However due to inequality in education system and social problems around them they are not able to perceive their higher education. According to students opinion majority of SC/ST students are lacking behind physical facilities which ultimately effect their education performance. The results obtained are given in Table 5 and the graphical representation of student response on higher education with respect to competition is given in Fig 4. 


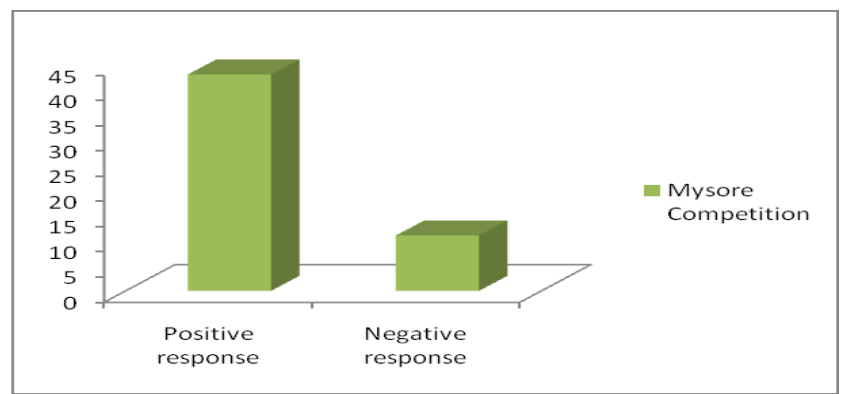

Figure4, Perception towards higher education with respect to lack of competition.

Students' perception with respect to Responsibility

\begin{tabular}{|l|l|c|c|c|}
\hline District & Factors & Positive response & Negative response & Positive Percentage (\%) \\
\hline Mysore & Responsibility & 49 & 5 & 91 \\
\hline
\end{tabular}

The respondents said that higher education is difficult to take because of various personal and professional responsibilities. Most of the respondents said that after graduation instead of perceiving higher education they opt for some jobs because of the less house hold income of their family and the responsibilities they are having. The results of the respondents with respect to responsibility are given in table 6 and the graphical representation of student's response on higher education with respect to responsibilities is given in Fig 5.

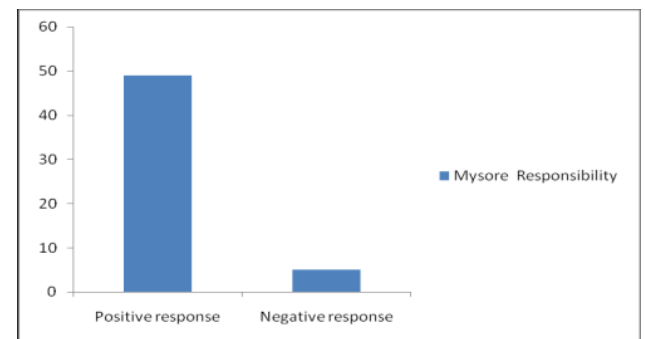

Figure5, Perception towards higher education with respect to lack of responsibility

\section{Conclusion}

The overall study reveals that the participation of SC/ST students for higher education is very low compared to other section of the society. The factors quoted in the present article which was revealed from primary data like inadequate finance, lack of awareness of benefits after obtaining the higher education, lack of basic infrastructure such as lap top facility, accommodation facilities and vehicle facilities are the most crucial factors affecting the SC/ST students in participating for higher education. It is well known that government has formulated policies and financial benefits exclusively for SC/ST student, however based on our study we can conclude that the policies formulated and financial benefits provided for SC/ST students has failed to brings the desirable result therefore government have take up proper corrective measures and should implement all policies and financial incentives in an effective manner to reduced the gap between SC/ST student and other students.

\section{References}

[1]. Asian Development Bank. (1989). Asian development outlook 1989. Manila, Asian Development Bank. In Lim, D. (1999). Quality assurance in higher education in Developing Countries. Assessment and Evaluation in Higher Education, 24 (4).

[2]. Denison, E. (1967). Why Growth Rates Differ: post-war experience in nine Western

[3]. Danaher.P (etc ) (2009). Transforming the Practice of Mobile Learning: Promoting Pedagogical Innovation through

[4]. Educational Principles and Strategies that Work. Innovative Mobile Learning: Techniques and Technologies, (pp 21-46).

[5]. Kinshuk, Chen J (2005 ). Mobile Technology in Educational Services. Journal of Educational Multimedia and Hypermedia, 14(1), 91-109.

[6]. Quality assurance in higher education in developing countries. Assessment and Evaluation in Higher Education, 24 (4).

[7]. Higher Education Commission, Pakistan's Website: www.hec.gov.pk/

[8]. Husain, I. (2007). Social sciences receiving due attention. HEC News and Views, a Monthly Magazine of Higher Education Commission.

[9]. Lemaitre, J.M. (2008). Impact of quality assurance processes in higher education institutions. Quality Assurance in Higher Education. HEC-Printing Press.

[10]. Mohanthy, J. (2000). Current trends in higher education. New Delhi India: Deep \& Deep.

[11]. Psacharopoulos, G. (1988). Education and development: a review, World Bank Research Observer, 3, pp. 99-116.

[12]. Rahman, A. (2007). Higher education in Pakistan: A Silent Revolution. Institute of Siddiqui, S. (2007). Rethinking education in Pakistan. Paramount Publishing Enterprise, Karachi, pp 152.

[13]. Tovey, P. (1992). Assuring quality: current practice and future directions in continuing professional education, Studies in the Education of Adults, 24, pp. 125-142.

[14]. www.tupc.bc.ca/publications/ur bro.pdf 